\title{
Mucormycosis prevalence in diabetic individuals in the northeast of Iran: a 10-year retrospective study
}

\author{
Roghieh Golsha $^{1}$, Nona Gorgitabar ${ }^{1}$, Behnaz Khodabakhshi ${ }^{1}$, Abdullah Abbasi ${ }^{1}$, Hamed Kalani ${ }^{1,2^{*}}$ \\ 1. Infectious Diseases Research Center, Golestan University of Medical Sciences, Gorgan, Iran \\ 2. Clinical Research Development Center, Sayad Shirazi Hospital, Golestan University of Medical Sciences, Gorgan, \\ Iran
}

\section{Article Type: \\ Original Article}

\section{Article History:}

Received: 30 Jan 2020

Revised: 11 Feb 2020

Accepted: 29 Feb 2020

\section{*Correspondence:}

Hamed Kalani,

Infectious Diseases Research Center, Golestan University of Medical Sciences, Gorgan, Iran hamed.kalani@yahoo.com

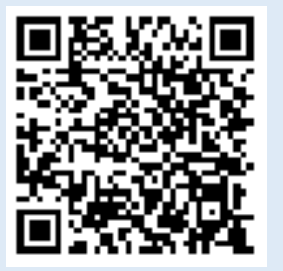

DOI: 10.29252/jorjanibiomedj.8.1.34

\begin{abstract}
Background and objective: Currently, due to an increase in the number of individuals with immune deficiency, long-term chemotherapy, and underlying diseases, an appropriate situation has been provided for the development of opportunistic infections, including fungal infections. This study was conducted with the aim of evaluating clinical symptoms, laboratory findings, and the treatment outcome of mucormycosis in diabetic individuals.

Methods: In this cross-sectional retrospective study, all recorded cases of mucormycosis in the health centers of Gorgan city, northeast of Iran, in diabetic individuals were extracted during 15 years from 2002 to 2016. All information was extracted from patient-related records and then was analyzed. In the period from 2002 to 2016, 12 diabetic individuals with mucormycosis were referred to health centers.

Results: There were statistically significant differences in the categories of sex, residence, education, taking drug, addiction, diabetes status, methods of diagnosis, involved area with mucormycosis, treatment type of mucormycosis, and treatment outcome of mucormycosis. Furthermore, no statistically significant difference was observed in the categories of age, underlying diseases (other than diabetes), hospitalization, and diagnostic time.

Conclusion: Due to the rareness or lack of an appropriate diagnostic method, and in addition, due to lack of an appropriate treatment, attention should be paid to invasive mucormycosis in individuals with immunodeficiency.
\end{abstract}

Keywords: Diabetes, Gorgan, Iran, Mucormycosis

Copyright $\subseteq$ 2018, Jorjani Biomedicine Journal has published this work as an open access article under the terms of the Creative Commons Attribution License (http://creativecommons.org/licenses/by-nc/4.0/) which permits noncommercial uses of the work while it is properly cited. 


\section{Introduction}

Currently, due to an increase in the number of individuals with immune deficiency, longterm chemotherapy, and underlying diseases, an appropriate situation has been provided for the development of opportunistic infections, including fungal infections [1]. Mucormycosis, is one of the fungal infections that can cause disease in these individuals. Infection in susceptible people is usually initiated from the nasal cavity or lung alveoli [2]. Moreover, this disease is capable of causing vascular and tissue damages in the invasive form [3]. Based on the conditions of the host's immune system and the organ involved, the disease is divided into five main forms, including rhino-orbito-cerebral, pulmonary, cutaneous, gastrointestinal, and central nervous system, from which the rhinoorbito-cerebral is the most common and serious form [4]. Moreover, invasive rhinoorbito-cerebral and pulmonary mucormycosis are associated with a poor prognosis $[5,6]$.

Members of the Mucoraccae family cause mucormycosis, and its members include Mucor spp., Rhizopus spp., and Absidia spp. [7, 8]. These organisms are mainly transmitted by air and easily grown and found in nature. Furthermore, their spores are usually not pathogen, and only where predisposing factors are available can cause the disease [9]. The most common predisposing conditions for this disease include diabetes mellitus, metabolic acidosis, taking glucocorticoids, organ transplantation, hematologic malignancies, acquired immune deficiency syndrome (AIDS), and iron accumulation.

Today, type 1 diabetes is one of the common autoimmune diseases so that new cases are increasingly being reported worldwide [10].
Fungal infections after diabetic foot syndrome are the most common problem in diabetic individuals, especially in advanced cases [1113].

Therefore, due to the high prevalence of diabetes and the high mortality rate of mucormycosis in individuals with underlying diseases, this study was conducted with the aim of evaluating the prevalence rate of mucormycosis in diabetic individuals with emphasis on clinical symptoms, laboratory findings, and the treatment outcome.

\section{Materials and Methods}

\section{Ethical considerations}

This study was approved by the Ethics Committee of the Golestan University of Medical Sciences, Gorgan, Iran (Ethical Code: 151029). All personal information of the individuals remained confidential.

\section{Study design}

In this cross-sectional retrospective study, all reported cases of mucormycosis in diabetic individuals documented at the health centers of Golestan Province, the north of Iran, were evaluated during 15 years from 2002 to 2016. All information was extracted from patientrelated records and then was analyzed.

\section{Data analysis}

Data was analyzed by IBM-SPSS v16 software (IBM SPSS Inc., Armonk, NY, USA) using statistical tests including twotailed t-test and chi-square, and the results were considered significant where the statistical difference was $<0.05$.

\section{Results}

In the period from 2002 to 2016, 12 diabetic individuals with mucormycosis were referred to the health centers in the north of Iran. Information extracted from the records of 
these individuals has been presented in Table

1. Three methods were used for these 12 mucormycosis cases, 9 of which were detected by biopsy method, and this method was more efficient than other ones.

Table 1. The variables and their frequency in diabetic individuals infected with mucormycosis

\begin{tabular}{|c|c|c|c|}
\hline Variable & Category & Number (\%) & P-value \\
\hline \multirow[t]{2}{*}{ Age } & $\leq 60$ & $5(41.66)$ & $>0.05$ \\
\hline & $>60$ & $7(58.33)$ & \\
\hline \multirow[t]{2}{*}{ Sex } & Man & $4(33.33)$ & $<0.05$ \\
\hline & Woman & $8(66.67)$ & \\
\hline \multirow[t]{2}{*}{ Residence } & Rural & $4(33.33)$ & $<0.05$ \\
\hline & Urban & $8(66.67)$ & \\
\hline \multirow[t]{4}{*}{ Education } & Literate & $2(16.67)$ & $<0.05$ \\
\hline & Under diploma & $4(33.33)$ & \\
\hline & Diploma & $5(41.66)$ & \\
\hline & Academic & $1(8.33)$ & \\
\hline \multirow[t]{7}{*}{ Underlying diseases (other than diabetes) } & HTN & $2(16.67)$ & $>0.05$ \\
\hline & IHD & $2(16.67)$ & \\
\hline & COPD & $1(8.33)$ & \\
\hline & HTN/HLP/IHD & $1(8.33)$ & \\
\hline & HTN/IHD & $1(8.33)$ & \\
\hline & HTN/CKD & $1(8.33)$ & \\
\hline & None & $4(33.33)$ & \\
\hline \multirow[t]{4}{*}{ Taking drug } & Insulin & $5(41.66)$ & $<0.05$ \\
\hline & Metformin & $5(41.66)$ & \\
\hline & Antibiotic & $1(8.33)$ & \\
\hline & None & $1(8.33)$ & \\
\hline \multirow[t]{2}{*}{ Addiction } & Yes & $4(33.33)$ & $<0.05$ \\
\hline & No & $8(66.67)$ & \\
\hline \multirow[t]{2}{*}{ Diabetes status } & Controlled & $3(25)$ & \multirow[t]{2}{*}{$<0.05$} \\
\hline & Not controlled & $9(75)$ & \\
\hline Hospitalization & $\leq 30$ & $5(41.66)$ & $>0.05$ \\
\hline
\end{tabular}




\begin{tabular}{|l|l|l|l|}
\hline & $>30$ & $7(58.33)$ & \\
\hline Diagnostic time $^{\mathbf{a}}$ & $\leq 7$ days & $6(50)$ & $>0.05$ \\
\hline & $>7$ days & $6(50)$ & \\
\hline Methods of diagnosis & Smear/culture & $2(16.67)$ & $<0.05$ \\
\hline & Biopsy & $9(75)$ & \\
\hline & Biopsy and CT ${ }^{\mathrm{b}}$ scan & $1(8.33)$ & \\
\hline Involved region with mucormycosis & Mouth & $1(8.33)$ & $<0.05$ \\
\hline & Nose & $1(8.33)$ & \\
\hline & Paranasal sinus & $2(16.67)$ & \\
\hline & Orbit & $2(16.67)$ & \\
\hline Treatment of mucormycosis & Lung & $5(41.66)$ & \\
\hline & Skin & $1(8.33)$ & \\
\hline & Amphotericin B & $4(33.33)$ & $<0.05$ \\
\hline & Amphotericin B/surgery & $7(58.33)$ & \\
\hline & AmphotericinB/Surgery/Antibiotic & $1(8.33)$ & \\
\hline & Improved and discharged & $9(75)$ & $<0.05$ \\
\hline & Transferred to other center & $1(8.33)$ & \\
\hline & Expired & $2(16.67)$ & \\
\hline & & & \\
\hline
\end{tabular}

\section{Discussion}

In many developing countries, the problem of increasing drug resistance in fungi to standard medicines on the one hand, and the lack of facilities for a definitive diagnosis on the other hand, makes it difficult to assess early detection of invasive fungal diseases while the number of individuals with immunodeficiency is increasingly being reported. After candidiasis and aspergillosis, mucormycosis is the third most common cause of invasive fungal infection. Spores from this group of fungi enter in the nasal and lung cavities through inhalation, and in subjects with immunodeficiency or a neutrophil functional disorder such as those with diabetes, tissue invasion may be observed. In this matter, the most frequently reported genus is Rhizopus spp. [14]. Clinical manifestations may be often observed in the form of rhino-orbito-cerebral or rhino

cerebral, but they can invade the lung, gastrointestinal tract, and rarely other organs, and can even be manifested as systemic infection [6, 15]. Effective chemoprophylaxis has not yet been known for mucormycosis and, in fact, the use of prophylactic regimens, including fluconazole and voriconazole, increases the risk of this disease. Apart from Amphotericin B, Posaconazole is the only new antifungal agent against this disease. The 
total mortality rate of mucormycosis is $49 \%$, while in the local forms the mortality rate is $41.9 \%$ and individuals with disseminated infection usually die $[6,16]$.

One of the reasons why mucormycosis is likely to be increased in people with diabetes is the presence of excess sugar in the body, providing conditions for these fungi to grow and replicate easily in the diabetic individuals' body. On the other hand, uncontrolled diabetes due to the presence of acidic substances in the blood provides appropriate growth conditions for these fungi, especially the genus Rhizopus spp. [17].

In a study on 22 diabetic individuals with mucormycosis, one quarter of the cases were found with immunodeficiency. Only $20 \%$ of the cases were identified by culture and the diagnosis was mainly based on biopsy [18], like what has been reported in the present study. It seems that in diabetic individuals with mucormycosis, early diagnosis, early surgery and necrotic tissue removal, appropriate antifungal therapy, and control of risk factors such as diabetes are the main parameters for successful management of this infectious disease [19]. It appears that the mortality rate of individuals with pulmonary mucormycosis is about $76 \%$ [20], while researchers in a study found that a lower mortality rate occur in individuals with only bronchial involvement due to the limited extent of the disease to the bronchial area [21].

Diagnosis of this disease is difficult because these fungi are not properly stained by routine laboratory stains and does not grow easily in the culture medium. The reliable diagnostic method for this fungus is microscopic examination [20]. The average time for diagnosis from the onset of the disease is about 16.2 days [22]. In the current study, this time was not different in two examined groups of $\leq 7$ days and $>7$ days.

\section{conclusion}

In conclusion, one of the most important issues in the treatment of individuals with mucormycosis is the timely diagnosis of the disease, which is often delayed due to the rareness or lack of an appropriate diagnostic method, and in addition, due to lack of appropriate treatment, the prognosis is often poor. In spite of this, the treatment outcome is related to several risk factors and should be remarkedly considered. Finally, attention should be paid to fatal diseases with low prevalence in individuals with immunodeficiency such as invasive mucormycosis.

\section{Conflict of interest}

The authors declare that they have no conflict of interest.

\section{Acknowledgments}

This work was supported by the Golestan University of Medical Sciences, Gorgan, Iran under Grant Number: 708.

\section{References}

1. Lanternier F, Cypowyj S, Picard C, Bustamante J, Lortholary O, Casanova JL et al. Primary immunodeficiencies underlying fungal infections. Curr opini pediatr. 2013;25(6):736-47. [DOI: 10.1097/MOP.0000000000000031]

\section{[DOI:10.1097/MOP.0000000000000031]}

2. Ferguson BJ. Mucormycosis of the nose and paranasal sinuses. Otolaryngol Clin North Am. 2000;33(2):349-65. [DOI: 10.1016/s00306665(00)80010-9] [DOI:10.1016/S00306665(00)80010-9]

3. Greenberg RN, Scott LJ, Vaughn HH, Ribes JA. Zygomycosis (mucormycosis): emerging clinical importance and new treatments. Curr 
opini infect dis. 2004;17(6):517-25. [DOI: 10.1097/00001432-200412000-00003] [DOI: 10.1097/00001432-200412000-00003]

4. Ruoppi P, Dietz A, Nikanne E, Seppa J, Markkanen H, Nuutinen J. Paranasal sinus mucormycosis: a report of two cases. Acta Otolaryngol. 2001;121(8):948-52. [DOI:10.1080/000164801317166844]

5. Ibrahim AS, Spellberg B, Walsh TJ, Kontoyiannis DP. Pathogenesis of mucormycosis. Clinical infectious diseases : an official publication of the Infectious Diseases Society of America. 2012;54 Suppl 1(Suppl 1):S16-S22. [DOI: 10.1093/cid/cir865]

\section{[DOI:10.1093/cid/cir865]}

6. Almyroudis NG, Sutton DA, Linden P, Rinaldi MG, Fung J, Kusne S. Zygomycosis in Solid Organ Transplant Recipients in a Tertiary Transplant Center and Review of the Literature. Am J Transplant. 2006;6(10):2365-74. [DOI: 10.1111/j.1600-6143.2006.01496.x]

\section{[DOI:10.1111/j.1600-6143.2006.01496.x]}

7. Dave SP, Vivero RJ, Roy S. Facial cutaneous mucormycosis in a full-term infant. Arch Otolaryngol Head Neck Surg. 2008;134(2):206-9. [DOI: 10.1001/archoto.2007.48]

\section{[DOI:10.1001/archoto.2007.48]}

8. Al-Obaidi M, Younes P, Ostrosky-Zeichner 138 L. Post-exposure prophylaxis with isavuconazole after occupational exposure to Rhizopus. Oxford medical case reports. 2018;2018(10):omy062.

[DOI:

10.1093/omcr/omy062]

[DOI:10.1093/omcr/omy062]

9. Turunc $\mathrm{T}$, Demiroglu YZ, Aliskan $\mathrm{H}$, Colakoglu S, Arslan H. Eleven cases of mucormycosis with atypical clinical manifestations in diabetic patients. Diabetes Res Clin Pract. 2008;82(2):203-8. [DOI: 10.1016/j.diabres.2008.07.011] [DOI:10.1016/j.diabres.2008.07.011]

10. You WP, Henneberg M. Type 1 diabetes prevalence increasing globally and regionally: the role of natural selection and life expectancy at birth. BMJ open diab res ca. 2016;4(1):e000161. [DOI: 10.1136/bmjdrc-2015-000161] [DOI:10.1136/bmjdrc-2015-000161]

11. Ilyas R, Wallis R, Soilleux EJ, Townsend P, Zehnder D, Tan BK et al. High glucose disrupts oligosaccharide recognition function via competitive inhibition: a potential mechanism for immune dysregulation in diabetes mellitus. Immunobiology. 2011;216(1-2):126-31. [DOI: 0.1016/j.imbio.2010.06.002]

\section{[DOI:10.1016/j.imbio.2010.06.002]}

12. Ata A, Lee J, Bestle SL, Desemone J, Stain SC. Postoperative hyperglycemia and surgical site infection in general surgery patients. Arch Surg. 2010;145(9):858-64.

[DOI:

10.1001/archsurg.2010.179]

[DOI:10.1001/archsurg.2010.179]

13. de Leon EM, Jacober SJ, Sobel JD, Foxman B. Prevalence and risk factors for vaginal Candida colonization in women with type 1 and type 2 diabetes. BMC Infect Dis. 2002;2:1. [DOI: 10.1186/1471-2334-2-1] [DOI:10.1186/14712334-2-1]

14. Ribes JA, Vanover-Sams CL, Baker DJ. Zygomycetes in human disease. Clin microbiol rev. 2000;13(2):236-301. [DOI: $10.1128 / \mathrm{cmr} .13 .2 .236-301.2000]$ [DOI:10.1128/CMR.13.2.236-301.2000]

15. Kolekar JS. Rhinocerebral mucormycosis: a 159 retrospective study. Indian $\mathrm{j}$ otolaryngol. 2015;67(1):93-6. [DOI:10.1007/s12070-0140804-5]

16. Lanternier F, Dannaoui E, Morizot G, Elie C, Garcia-Hermoso D, Huerre $M$ et al. A global analysis of mucormycosis in France: the RetroZygo Study (2005-2007). Clin Infect Dis. 2012; 54 Suppl 1:S35-43. [DOI: 10.1093/cid/cir880] [DOI:10.1093/cid/cir880]

17. Afroze SN, Korlepara R, Rao GV, Madala J. Mucormycosis in a Diabetic Patient: A Case Report with an Insight into Its Pathophysiology. Contemp clin dent. 2017;8(4):662-6. [DOI: 
10.4103/ccd.ccd_558_17]

[DOI:10.4103/ccd.ccd_558_17]

18. Gutiérrez-Delgado EM, Treviño-González JL, Montemayor-Alatorre A, Ceceñas-Falcón LA, Ruiz-Holguín E, Andrade-Vázquez CJ et al. Chronic rhino-orbito-cerebral mucormycosis: A case report and review of the literature. Ann surg. 2016;6:87-91.

[DOI:

10.1016/j.amsu.2016.02.003]

[DOI:10.1016/j.amsu.2016.02.003]

19. Mohammadi R, Meidani M, Mostafavizadeh K, Iraj B, Hamedani P, Sayedain SM et al. Case series of rhinocerebral mucormycosis occurring in diabetic patients. Caspian journal of internal medicine. 2015;6(4):243-6.
20. Iqbal N, Irfan M, Jabeen K, Kazmi MM, Tariq MU. Chronic pulmonary mucormycosis: an emerging fungal infection in diabetes mellitus. $\mathbf{J}$ thorac dis. 2017;9(2):E121- e5. [DOI: 10.21037/jtd.2017.02.31]

[DOI:10.21037/jtd.2017.02.31]

21. Parham M, Abbasi M, Alipour Nodoushan K, Noorozi M, Mehran N. A Case Report of Rare Tracheal Mucormycosis in a Diabetic Patient. Qom Univ Med Sci J. 2009;3(3):57-60.

22. Kashkouli MB, Abdolalizadeh P, Oghazian M, Hadi Y, Karimi N, Ghazizadeh M. Outcomes and factors affecting them in patients with rhinoorbito-cerebral mucormycosis. $\mathrm{Br} \mathrm{j}$ ophthalmol. 2018. [DOI: 10.1136/bjophthalmol-2018-312688] [DOI:10.1136/bjophthalmol-2018-312688]

\section{How to cite:}

Golsha R, Gorgitabar N, Khodabakhshi B, Abbasi A, Kalani H. Mucormycosis prevalence in diabetic individuals in the northeast of Iran over: a 10-year retrospective study. Jorjani Biomedicine Journal. 2020; 8(1): 34-40. 